\title{
Influence of Expressway Construction on the Ecological Environment and the Corresponding Treatment Measures: A Case Study of Changyu (Changchun- Fuyu Lalin River) Expressway, China
}

\author{
Gao Jiayin*, Zhang Mingfei**, Hu Zhaoguang** and Shan Wei***† \\ *College of Engineering and Technology, Northeast Forestry University, Harbin 150040, China \\ **College of Civil Engineering and Architecture, Zhengzhou University of Aeronautics, Zhengzhou, 450046, China \\ ***Institute of Cold Regions Science and Engineering, Northeast Forestry University, Harbin 150040, China. \\ †Corresponding author: Shan wei; shanwei456@163.com
}

Nat. Env. \& Poll. Tech.

Website: www.neptjournal.com

Received: 23-04-2020

Revised: $15-06-2020$

Accepted: 14-07-2020

Key Words:

Expressway construction

Ecological environment

Treatment measures

Changyu expressway

\begin{abstract}
With astounding advances, China expressway construction has caused inevitable environmental destruction around the construction projects. A series of expressway construction-induced environmental problems is caused by the noise pollution of machinery and equipment in expressway construction, atmospheric pollution caused by fuel consumption, soil contamination caused by abandoned waste materials and gases generated by asphalt mixture during road paving, and increasing traffic volume. In this study, the literature regarding expressway construction-induced environmental pollution was combined by taking Changyu (Changchun-Yulin Lalin River) Expressway as an example. The impacts of expressway construction on the ecological environment were analyzed, and feasible treatment measures were proposed. Results show that the expressway construction in various countries across the globe aggravates the regional ecosystem damage unavoidably to a certain extent; The environmental impacts caused by Changyu Expressway are manifested at five aspects, namely, water environmental pollution, vegetation deterioration, heavy metal pollution, water and soil losses, and induction of geological disasters; The environmental impacts of expressway construction can be mitigated by reasonable route selection, strengthening planning and environmental protection, preventing water and soil losses, reinforcing atmospheric pollution detection, reducing sewage discharge, enhancing vegetation recovery, and relieving the impact on animal habitats. The study results serve as an important reference for identifying the sources of expressway environmental risks and lowering the environmental pollution caused by expressway construction to an acceptable level.
\end{abstract}

\section{INTRODUCTION}

The expressway construction in China is developing at considerable speed. As shown in Fig. 1, the total mileage of China expressways has rapidly increased from 16,200 $\mathrm{km}$ in 2000 to $149,600 \mathrm{~km}$ in 2019 , and the annual average growth rate has reached $43 \%$. However, the rapid advancement of expressway construction has brought unavoidable environmental destruction around the construction projects. Under frequent human activities, the ecological environment experiences irreversible pollution and destruction and threatens human health and survival. Sustainable development is advocated within the global scope at present. As a livelihood project, expressway engineering must consider environmental benefits when creating economic benefits. The high-speed construction of expressway projects has caused serious environmental problems in the affected zones along the expressways. These environmental problems include biodiversity degradation and disordered biological clock of animals and plants, water and soil losses, motor vehicle exhaust emission and noise generated by road traffic vehicles along the expressways, ecological and natural environmental quality problems and socioeconomic environmental phenomenon, such as water environmental pollution, caused by transportation of dangerous chemicals. However, high filling and deep excavation are unavoidable during expressway construction, and bridging by tunnelling through mountains is common, resulting in environmental destruction.

Given that wide black bituminous pavements commonly used on expressways have strong heat absorptivity, along with increased coverage area of roadside desertification land, the surface temperature along the expressways is elevating, thereby accelerating permafrost thawing within the expressway region and leading to pavement drying and grassland degeneration. This condition accelerates the desertification progress within the expressway region and degrades its ecological environment. The linear cutting action of expressways 


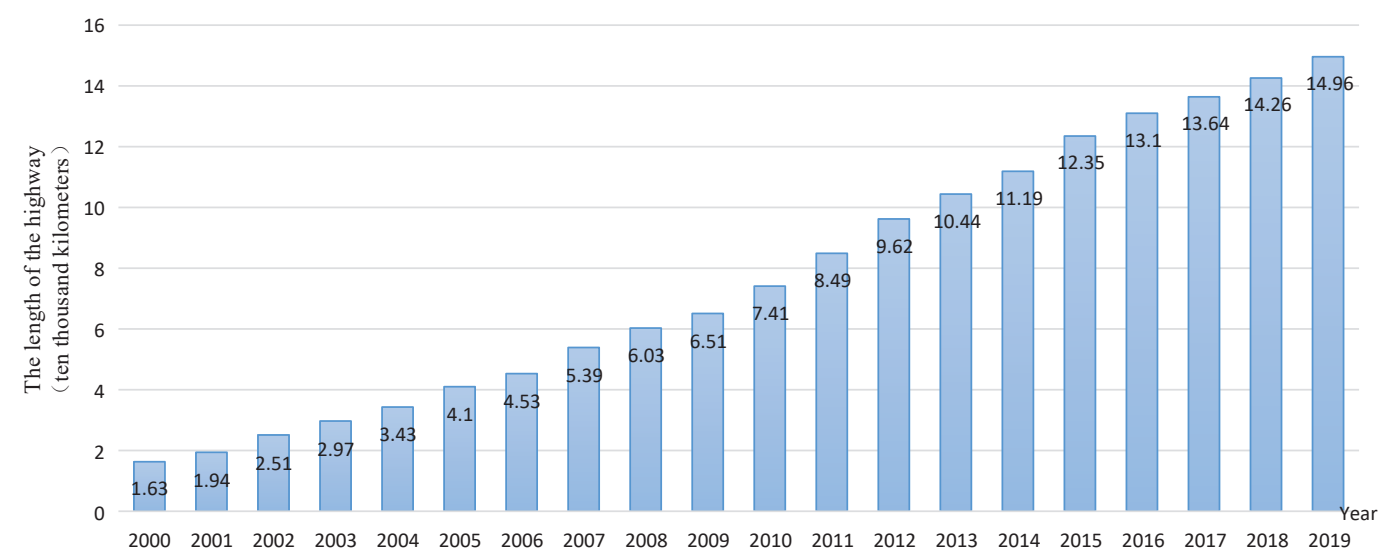

Fig. 1: Expressway mileages in China during 2000-2019.

aggravates the ecological environment deterioration. Therefore, field investigation must be first conducted to deeply analyze the possible adverse effects of various engineering construction links on the surrounding environment and evaluate the severity of such effects following the involved scope of influence to achieve expressway environmental protection. A practical and feasible protection scheme can be formulated. Environmental protection should be prioritized in actual expressway construction links, such as construction design and technological application. Improving environmental protection functions of highways can lengthen their service life and mitigate environmental destruction caused by engineering construction.

\section{PAST STUDIES}

An expressway is an important mark of modernization of a country and its transportation and major infrastructure in national economic and social development. Expressway construction plays an important role in promoting national economic development, reasonable productivity distribution, and interregional cooperation, improving the investment environment, raising the living standard, promoting the domestic demand, and stimulating the economic development and prosperity of regions nearby the expressways. However, expressway construction projects generate major and far-reaching influences on the wide-range ecological environment within a large region during the construction and operation periods. For the environmental impacts of expressways and their control measures, Foppen (1994) believed that road construction is a double-edged sword, where it accelerates economic development and transformation of transportation modes but causes immeasurable losses to the natural environment and results in environmental separation from landscapes. Reijnen et al. (1995) studied the influences of motor traffic on bird breeding density in deciduous and coniferous forests and the importance of automobile noise and visibility as possible factors influencing the bird breeding density. Forman et al. (2000) thought that traditional transportation planning has an evident influence on eco flow and biodiversity. They estimated the influence positions and distances of nine processes by taking a suburban four-lane expressway with $24 \mathrm{~km}$ in length in Boston as an example. The study results indicated the impact of expressway traffic noise on bird communities and showed that the road extends outward for more than $100 \mathrm{~m}$ as the barrier disturbing the wildlife tourism aisle. Geneletti (2003) deemed that the road network is an important reason for the declining quantity and quality of natural habitats and proposed a road project BIA (Biodiversity Impact Assessment) method that can be used to directly analyze the expressway construction-induced direct ecosystem loss. Viard et al. (2004) monitored the heavy metal content in soil at the two sides of French A31 Expressway, and the results indicated that the maximum pollution ranges from $5 \mathrm{~m}$ to $20 \mathrm{~m}$. Xu et al. (2006) elevated the expressway subgrade in permafrost region to mitigate the influence of freeze-thawing on the road stability of alpine steppe with low vegetation coverage. However, mostly sands and grits are found on the expressway slope, thereby improving the erosion potential of slope soil. Xia et al. (2007) found that vegetation destruction of the highway construction phase, linear road cutting, and automobile running limit the utilization of wildlife aisles. The influence of transportation development on Tibetan antelope habitat and migration is the present and future primary factor threatening Tibetan antelopes. Hjortenkrans et al. (2008) analyzed the heavy metal content in exposed soil along the two highways in Sweden and pointed out that the heavy metal content in $0-10 \mathrm{~cm}$ soil is remarkably higher than that in $10-30 \mathrm{~cm}$ soil. Given that road 
is a linear source of pollution, the heavy metals in soil present highway-centred and two side-extended banding distribution laws. Bukowiecki et al. (2010) considered that non-exhaust emissions generated by highway operation generate a large load on the air environment in the road region. These emissions mainly include particles formed by the resuspension of sedimentary road dusts, which are caused by automobile braking wear, tyre wear, pavement wear, and vehicles. Yan et al. (2013) investigated the heavy metal contents in surface soil within the road region distant from villages, towns, and region of industrial and agricultural activities. They found that the heavy metal concentration in surface soil exponentially declines with lowered ecological risks with the increase in distance from the road boundary through field investigation and laboratory experiment. Karlson et al. (2014) believed that road construction exerts extensive impacts on terrestrial and aquatic ecosystems, and the road network is increasingly associated with biodiversity loss across the world (Karlson et al. 2014). Zhang et al. (2015) explored the heavy metal enrichment degree in soil along Tibetan expressways and found that the heavy metal content is the highest in soil on the alpine steppe, followed by those in alpine meadow and alpine desert. Zhang et al. (2017) investigated the heavy metal pollution and assessed the ecological risks along six roads of different land-use types in Sachsen State in Germany. The results showed that the surface load of $\mathrm{Zn}$ and $\mathrm{Cu}$ presents a declining trend from the city centre toward the urban fringe. Taking China as an individual case, Wu et al. (2019) discussed the governmentally perceived scope of environmental impacts and the transformation of concepts into management methods. The results showed that the government can effectively improve the environmental and ecological protection level by strengthening the environmental management of expressways. Existing literature shows that the expressway construction has entered a rapid development phase across the globe, and the expressway construction has unavoidably aggravated the regional ecosystem destruction to a certain extent, thereby deteriorating the ecological environment along expressways and impacting their environmental quality. The environmental impacts of expressway construction were analyzed, and control measures were proposed by taking Changyu Expressway as an example. The findings serve as a reference for enriching the evaluation system for the environmental impacts of expressways and mitigating the environmental pollution caused by expressway construction and operation.

\section{BASIC INFORMATION OF CHANGYU EXPRESSWAY}

\section{Natural Environment}

The Changyu Expressway project is located in Fuyu City, Jilin Province. The geographic position coordinates of the project are east longitude of $125^{\circ} 57^{\prime}-126^{\circ} 05^{\prime}$ and northern latitude of $44^{\circ} 56^{\prime}-45^{\circ} 08^{\prime}$. This area belongs to a mid-temperate-zone continental monsoon climate with four distinctive seasons, which is dry and windy in spring and hot and rainy in summer with short autumn and long and cold winter. Changyu Expressway K1097+100-K1097+860 belongs to a soft soil foundation segment. A temperature monitoring equipment was buried at the right slope foot of K1097+200 section to perform sustainable long-time monitoring to understand the change in surface temperature in the study area. The surface temperature data are shown in Fig. 2. As shown in the surface temperature profile, the study area enters the frost period at the beginning of November, the seasonally frozen ground is unthawed until the end of April, the earth freeze-up time lasts for 5.5 months, and the maximum depth of seasonally frozen ground reaches $1.8 \mathrm{~m}$. Thus, it belongs to a severe cold area.

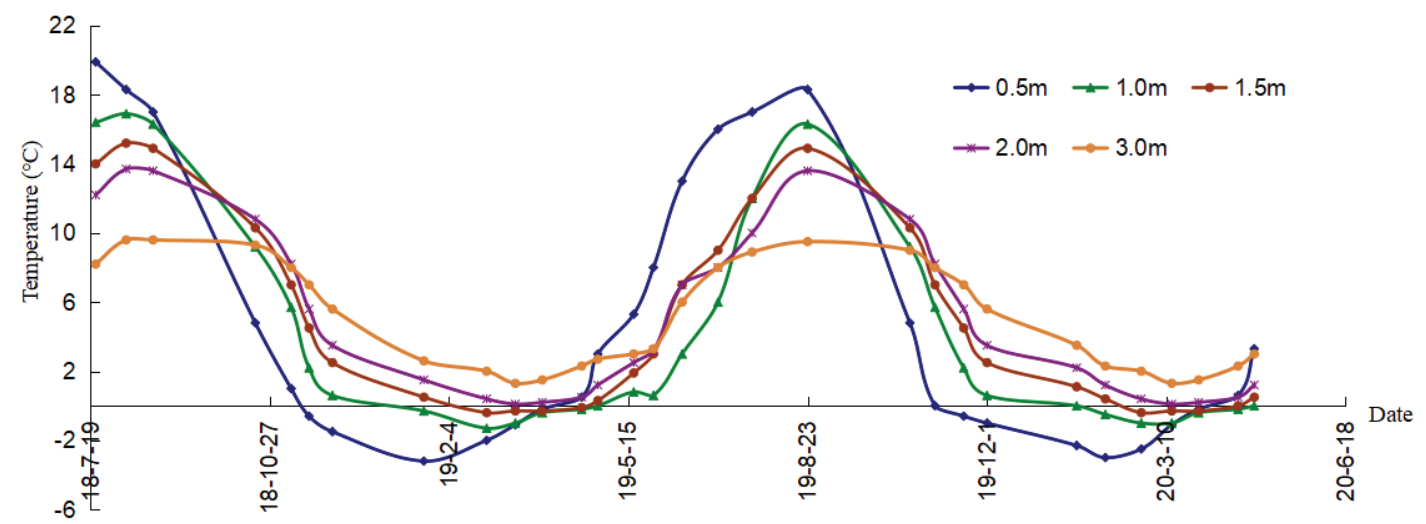

Fig. 2: Time-dependent change curves of surface temperature at the right slope foot of K1097+200. 


\section{Engineering Geological Conditions}

The Changyu Expressway project belongs to the flood plain landform in the east of Songliao Plain. During the geological survey of this road segment, the drilling results show that the $0-15 \mathrm{~m}$ depth range is quaternary Holocene alluvium. The groundwater type within the range of surveying depth in this area is loose rock-type porewater. The groundwater level is shallow at the sand layer, ranging from $7.5 \mathrm{~m}$ to 8.5 $\mathrm{m}$. The strata in this area are described from top to bottom as follows: (1) Silty clay: yellow, plastic, and slightly wet. The moisture content is within $12.8 \%-29.0 \%$, and the burial depth of the roof is 0-3.2 m. (2) Mucky soil: grey, with thickness ranging from $3.5 \mathrm{~m}$ to $7.5 \mathrm{~m}$, moist, soft plastic or fluid plastic, and paddy field segment. The moisture content is within $31.9 \%-43.6 \%$, and the strata thickness is within 3.5 m-7.5 m. (3) Fine sand: grey, slightly dense, saturated, and the main components are quartz and feldspar. The burial depth of the roof is 3.2-7.8 m. In the drilling reconnaissance, a soil sampler was used to collect several groups of undisturbed soil samples at the silty clay and mucky soil layers. Physical and mechanical property laboratory experiment of the collected samples was performed following the geotechnical testing regulations, and the soil physical and mechanical test indexes of different strata were obtained, including moisture content, unit weight, natural density, void ratio, specific gravity, cohesion, and internal friction angle, as presented in Table 1. The moisture content in mucky soil is high in the study area with weak soil mass strength. Thus, it belongs to a soft soil layer.

\section{ECOENVIRONMENTAL IMPACTS OF CHANGYU EXPRESSWAY CONSTRUCTION}

\section{Water Environmental Pollution}

Changyu Expressway construction threatens drinking water safety in the water conservation areas and is closely related to people's health and social stability. Some drinking water and surface water conservation areas are rivers and conveyance canals with large drainage area and long flowing length. Expressway construction certainly passes through or spans in some drinking water and surface water conservation areas. During the construction period, the generated pollutants and water and soil losses will be diffused into water sources, thereby leading to water pollution. The construction materials, such as asphalt, oil, and chemicals, will cause water environmental pollution if improperly kept and washed by rainwater to enter the water body during the construction period. In the construction period of the riverside road segment, the soil will be washed by rainwater into the river during subgrade and pavement construction, thereby causing partially high content of suspended matter in the river. Production wastewater in the construction period, domestic wastewater of the construction camps, and sewage from toll station and curing area in the operation period will generate adverse effects on the surrounding water body.

\section{Vegetation Damage}

Changyu Expressway is located in a flat area. Intensely disturbed by human activities, natural vegetations are mainly drought-resistant, barren, and heliophilous herbs, along with some heliophilous undershrub, and the biomass is low. Different from plants, animals are mobile and can proactively avoid damage. Changyu Expressway project construction will not generate an extreme effect on the diversity or population quantity of bird and reptile-type wildlife species, especially on the degradation of bird diversity, and will not have any influence on wildlife habitats. The heaps of debris during the construction will induce rats, mosquitos, snakes, and frogs. However, these living organisms will seek habitats again after the construction is completed. The noise, light, waste gas, vibration, and pavement runoff pollutants in the operation period will pollute the living environment of animals, break their original life pace, reduce their living environmental quality, and force them to seek for other activity and living places. This expressway belongs to a closed project with a certain obstructing effect on animals. However, a certain quantity of bridges and culverts is reserved in the design phase for animals to pass through the expressway. The animals present two-side extended distribution along the expressway, which is taken as aisle. Thus, this expressway has a minor obstructing effect on normal animal communication and foraging.

\section{Heavy Metal Pollution}

The heavy metal pollution generated by expressway transportation mainly derives from fuel consumption, wear of automobile metal parts and tyres, and chemical substances

Table 1: The summary sheet of physical and mechanical indexes of foundation soil in the test segment.

\begin{tabular}{|llllllll|}
\hline Soil type & Moisture content & $\begin{array}{l}\text { Unit weight } \\
\gamma_{\omega}\left(\mathrm{kN} / \mathrm{m}^{3}\right)\end{array}$ & $\begin{array}{l}\text { Natural density } \\
\left(\mathrm{g} / \mathrm{cm}^{3}\right)\end{array}$ & Void ratio & $\begin{array}{l}\text { Specific } \\
\text { gravity }\end{array}$ & $\begin{array}{l}\text { Cohesion } \\
(\mathrm{kPa})\end{array}$ & $\begin{array}{l}\text { Internal friction angle }\left(^{\circ}\right) \\
\text { Silty clay }\end{array}$ \\
Mucky soil & $35.1 \%$ & 17.2 & 1.96 & 0.83 & 2.75 & 40.95 & 21.5 \\
\end{tabular}


released by pavement materials and curing chemicals. The heavy metals are diffused in the particulate form together with atmospheric diffusion in tail gas form, pavement sputtering dust diffusion, and surface runoffs, and are accumulated in the soil at the two sides of the road. The generated polluting metallic elements come from fuels, engine oil, tyre wear, braking wear, and vehicle exhaust catalysts. The mass monitoring data manifest that the soil at the two sides of Changyu Expressway is polluted by toxic metallic elements to different degrees where the pollution caused by $\mathrm{Pb}$ and $\mathrm{Cd}$ is the most serious, followed by $\mathrm{Zn}$ and $\mathrm{Cu}$.

\section{Water and Soil Losses}

During the main construction process of Changyu Expressway, the construction links, such as subgrade and mountain excavation, and construction of a large number of tunnels, bridges, and culverts generate many spoils and waste slags, resulting in farmland and vegetation damage and exposed surface and degradation of soil erosion durability. The surface soil should be first peeled off and stored and backfilled when soil is collected in the borrow area, easily causing water and soil losses because of rainfall or gale weather. The slope formed by piling of spoils and waste slags will easily undergo water erosion and serious man-made water and soil losses and will induce debris flow disaster if not protected with engineering measures or afforestation measures. Many construction roads will be built in the construction period, and numerous heavy trucks running on the road during the construction will damage the pavement and generate a large quantity of raised dust. Stock ground, mixing field, and precast yard stacked with soils, stones, and sands will also experience serious water and soil losses if they are untimely protected as requested.

\section{Geological Disaster}

The expressway construction-induced landslide mainly occurs during the construction process. For instance, mountain excavation reduces the supporting force of slope rock mass and triggers landslide. Taking earth at the slope foot may cause landslide at the fragile part of the slope. In the zone with unstable rock masses, engineering blasting activity will trigger landslides. In the mountainous area, a landslide triggered by expressway construction is the main geological disaster. Abandoning spoils and building structures at the trailing edge of ancient landslide enlarges the additional stress, and thrust load-type landslide is generated because of increasing gliding force. Excavating a large quantity of earthwork will intercept the shallow buried aquifer and destruct shallow groundwater system, making it impossible for underground water to flow toward lower reaches, causing outcrop of groundwater appearing at cutting slope or sub- grade bottom, degrading the stability of highway subgrade and slope, and causing a landslide. A geological disaster, which is a common existence in the expressway construction process with strong destructive effect, is debris flow. During the expressway construction process, the vegetations along the expressway will be damaged, the bare area of soil mass will be increased, and enormous spoils will be generated because of earth excavation, these conditions result in many loose matter sources for the occurrence of debris flow, and heavy rainfall highly induces debris flow.

\section{ENVIRONMENTAL PROTECTION MEASURES IN CHANGYU EXPRESSWAY CONSTRUCTION}

\section{Reasonable Route Selection and Strengthened Planning}

Reasonable route selection is the precondition for relieving the negative eco-environmental impacts of expressway construction. The route selection should evade areas with good forest cover or eco-environmentally sensitive areas with special functions and occupy less cultivated land, especially basic farmland. High-tech surveying methods and monitoring means, such as precise surveying and mapping and reconnaissance via $3 \mathrm{~S}$ technology, should be adopted in reasonable route selection. The expressway should be kept away from segments with unstable geological conditions, such as fracture and karst cave, to prevent geological disasters in the construction process. The route selection scheme should be optimized to obtain a route selection scheme considering economic and ecological benefits. Environmental protection and ecological experts can be invited to participate in the entire expressway planning and design and evade some foreseeable problems. The experience and lessons should be summarized and problem causes should be analyzed following the planning and design based on the construction conditions of the already completed project and the ecological environmental status of the project to be constructed. The next stage of work should be concretely arranged after overall planning and coordination to ensure that ecological priority principle is conducted. The coordination with the surrounding environment should be realized as possible to promote the entire green expressway construction.

\section{Strengthen Environmental Protection and Prevent Water and Soil Losses}

The ecological environmental protection work must be timely tracked in the expressway construction process, including water and soil conservation and prevention of water and soil losses. Earth excavation and backfilling should not be conducted in the rainy season. The average precipitation is large in the south and small in the north of Jilin Province 
where Changyu Expressway is located, and many mountains but few hills are found in this area. The precipitation is larger than those on plains and hills of the same latitude because of high altitude. The precipitation distribution is relatively nonuniform in Jilin Province in different seasons, and the rainy season in the south is different from that in the north. Therefore, the rainfall laws in different areas should be understood in Changyu Expressway construction, earth excavation and backfilling should be completed, and water and soil conservation work should be conducted to prevent secondary disasters, such as water and soil losses before the rainy season comes. Slope protection measures, including slope cutting or graded slope cutting, should be taken. During the subgrade excavation process, temporary settling pond should be set where surface runoffs meet to intercept sediments brought by the surface runoffs. After the subgrade is built, the settling pond should be timely bulldozed for plant plantation or land reclamation. Different water and soil conservation measures should be taken in different stages in accordance with the project features. The soil and water conservation measures in the construction period should centre on engineering measures, assisted by biological control measures. The site of the borrow area should be reasonably planned and original spoils should be scientifically utilized. In the operation phase, high importance should be attached to subgrade slope protection, and flexible slope protection-dominated biological environmental engineering technologies should be used under most circumstances. These conditions can improve landscapes and contribute to ecological self-recovery in the natural recovery period.

\section{Enhance Atmospheric Pollution Detection and Reduce Sewage Discharge}

Atmospheric pollution is mainly controlled during the operation period. Although the raised dust in the construction period will generate adverse effects on field constructors and periphery villagers, extremely good dust removal effect can be reached by watering on the construction site. The primary atmospheric pollution source in the expressway project is motor vehicle exhaust emission during the operation period. During the operation period, related departments should strictly conduct motor vehicle exhaust emission testing system and forbid vehicles with exhaust gas emission exceeding the limit to run on the road through spot check at toll stations. The quality of oil products should be strictly controlled at gas stations in service areas along the expressway to reduce pollutant discharge from the source. The sewage discharge should be reduced through optimization design. The sewage discharge system in the expressway area and domestic sewage treatment scheme for supporting facilities have great water environmental impacts in the expressway project. Measures should be taken as early as the construction planning phase of Changyu Expressway. Surface drainage will be mixed with oil leaked by automobiles. Thus, pavement sewage should be discharged into a biological pond for oil removal, sedimentation, and purification or it may be discharged into the urban sewage treatment system together with domestic sewage generated by supporting facilities.

\section{Reinforce Vegetation Recovery and Lessen Impacts on Animal Living Environment}

The existing roads should be used to transport building materials or earth as possible. All types of vehicles should strictly run on the existing roads or the built construction roads and should not take shortcuts because this may grind crops and surface vegetations. Crops and vegetations around the construction site should not be destructed, temporary facilities and temporary projects should be reasonably planned and designed, and arbitrary construction should be forbidden. The construction areas involving forest land and fire risk should be monitored during the construction period to prevent fire disasters. The trees should be moved out for afforestation at other places when deforestation is essential for the main construction and temporary land use. Plants should be cultivated on the slope and new plant communities can be established to reach the goals of recovering the ecology and controlling water and soil losses. The afforestation project should highlight the characteristics of Anhui, centre on block plantation with prominent large colour lumps and large lines. Safety and environmental aesthetic effect should be considered, and attention should be paid to unification and coordination of road cultural and greenery landscapes. Wildlife aisle should be set below the main works to ensure normal foraging, reproduction, and interpopulation connections. The corresponding dedicated animal aisles should be set or the number of highway culverts should be increased and animal, deceleration, and no totting signs should be set at road segments where nationally protected wild animals come and go, including road segments where endangered species pass through. The forest region construction scheme should be optimized, the construction progress should be accelerated, the construction time in the forest region should be shortened, and blasting operation should be avoided to the greatest extent to avoid disturbing wild animals. The construction in the peak period of wild animal activities should be avoided, such as avoiding high-noise operations, such as blasting and piling in the morning, at dusk, and in the evening. Building materials, cement, oil products, and chemicals containing hazardous substances should not be stacked nearby water bodies, such as rivers and lakes, and wastes in the construction should not be locally poured or thrown into water bodies. 


\section{CONCLUSION}

The ecological environmental impacts of expressway construction projects in China are mainly manifested by surface vegetation damage in areas along the expressways and land occupation and ecological problems and water and soil losses arising out of the expressway construction. Taking reliable and feasible control measures in the expressway construction period can reduce the destruction of the ecological environment on the two sides of the expressway to the minimum level. Taking Changyu Expressway in China as an example, the literature regarding environmental pollution caused by expressway construction were combined, and the ecological environmental impacts of expressway construction were analyzed in this study. The study results manifest that the expressway constructions around the world have unavoidably aggravated the destruction of regional ecosystems. Changyu Expressway has formed environmental impacts in five aspects, namely, water environmental pollution, vegetation deterioration, heavy metal pollution, water and soil losses, and geological disaster. The proposed measures include strengthening expressway construction planning, preventing water and soil losses, enhancing waste gas and sewage detection, and reinforcing vegetation and animal protection. Future in-depth studies, including continuing grading evaluation of ecological environmental impacts of expressway construction projects, perfecting environmental evaluation index system and ecological environmental influence model of expressway region, and improving the evaluation method of ecological risk and human health risk caused by expressways, should be conducted.

\section{REFERENCES}

Bukowiecki, N., Lienemann, P., Hill, M., Furger, M., Richard, A., Amato, F., Prévôt, A., Baltensperger, U., Buchmann, B. and Gehrig, R. 2010. $\mathrm{PM}_{10}$ emission factors for non-exhaust particles generated by road traffic in an urban street canyon and along a freeway in Switzerland. Atmospheric Environment, 44(19): 2330-2340.
Foppen, R. R. 1994. The effects of car traffic on breeding bird populations in woodland. i. evidence of reduced habitat quality for willow warblers (Phylloscopus trochilus) breeding close to a highway. Journal of Applied Ecology, 31(1): 85-94.

Forman, R. T. T. and Deblinger, R. D. 2000. The ecological road-effect zone of a Massachusetts (U.S.A.) Suburban Highway. Conservation Biology, 14(1): 36-46.

Geneletti, D. 2003. Biodiversity impact assessment of roads: An approach based on ecosystem rarity. Environmental Impact Assessment Review, 23(3): 343-365.

Hjortenkrans, D. S. T., Bergbäck, B. G. and Häggerud, A. V. 2008. Transversal immission patterns and leachability of heavy metals in road side soils. J. Environ. Monit., 10(6): 739-746.

Karlson, M., Moertberg, U. and Balfors, B. 2014. Road ecology in environmental impact assessment. Environmental Impact Assessment Review, 48: 10-19.

Reijnen, R., Foppen, R. and Thissen, B. J. 1995. The effects of car traffic on breeding bird populations in woodland. III. Reduction of density in relation to the proximity of main roads. Journal of Applied Ecology, 32(1): 187-202.

Viard, B., Pihan, F., Promeyrat, S. and Pihan, J. 2004. Integrated assessment of heavy metal $(\mathrm{Pb}, \mathrm{Zn}, \mathrm{Cd})$ highway pollution: Bioaccumulation in soil, Graminaceae and land snails. Chemosphere, 55(10): 1349-1359.

Wu, L., Ye, K., Gong, P. and Xing, J. 2019. Perceptions of governments towards mitigating the environmental impacts of expressway construction projects: A case of China. Journal of Cleaner Production, 236: 117704.

Xia, L., Yang, Q., Chao, L., Wu, Y. and Feng, Z. 2007. The effect of the Qinghai-Tibet railway on the migration of Tibetan antelope Pantholops hodgsonii in Hoh-xil National Nature Reserve, China. Oryx, 41(3): 352-357.

Yan, X., Gao, D., Zhang, F., Zeng, C., Xiang, W. and Zhang, M. 2013. Relationships between heavy metal concentrations in roadside topsoil and distance to road edge based on field observations in the Qinghai-Tibet Plateau, China. International Journal of Environmental Research and Public Health, 10(3): 762-775.

Xu, X., Zhang, K., Kong, Y., Chen, J. and Yu, B. 2006. Effectiveness of erosion control measures along the Qinghai-Tibet highway, Tibetan plateau, China. Transportation Research Part D: Transport and Environment, 11(4): 302-309.

Zhang, H., Wang, Z., Zhang, Y., Ding, M. and Li, L. 2015. Identification of traffic-related metals and the effects of different environments on their enrichment in roadside soils along the Qinghai-Tibet highway. Science of the Total Environment, 521: 160-172.

Zhang, J., Hua, P. and Krebs, P. 2017. Influences of land use and antecedent dry-weather period on pollution level and ecological risk of heavy metals in road-deposited sediment. Environmental Pollution, 228: 158-168. 